\title{
Konjonktival Pterjium Etyopatogenezinde Sistemik İnflamasyonun Rolünün Değerlendirilmesi
}

\author{
Hanife Tuba AKÇAM 國
}

\section{ÖZ}

Amaç: Konjonktival pterjiumlu hastalarda hemogram parametreleri ve kan temelli sistemik inflamasyon belirteçlerinin düzeylerinin incelenmesidir.

Gereç ve Yöntemler: Çalışmaya konjonktival pterjiumu olan 30 hasta ve yaş-cinsiyet uyumlu 31 sağlıklı gönüllü dahil edildi. Tüm olgulara detaylı oftalmolojik muayene yapıldı. Ayrıca pterjium grubundaki olgularda pterjium derecelendirilmesi yapıldı. Tüm olgulardan serum örnekleri toplandı ve nötrofil/lenfosit oranı, platelet/lenfosit oranı ve sistemik immün-inflamasyon indeksi hesaplandı. Gruplar arasında nötrofil say1-yüzdesi, lenfosit sayı-yüzdesi, hemoglobin, eritrosit sayısı, lökosit sayısı, ortalama trombosit hacmi, eritrosit dağılım genişliği, trombosit sayısı, nötrofil/lenfosit oranı, platelet/lenfosit oranı, sistemik immün-inflamasyon indeksi arasında ilişki olup olmadığı incelendi. İstatistiksel analizde Ki-kare testi, Bağımsız örneklemler t-testi, Mann-Whitney U testi, Pearson ve Spearman korelasyon analizleri kullanıldı. $\mathrm{P}<0.05$ düzeyi istatistiksel olarak anlamlı kabul edildi.

Bulgular: Gruplar hücre sayıları açısından benzerdi. Nötrofil/lenfosit oranı ve platelet/lenfosit oranı pterjium grubunda hafifçe yüksek olmakla birlikte bu fark istatistiksel açıdan anlamlı değildi (sırasıyla $\mathrm{P}=0.141, \mathrm{P}=0.480$ ). Sistemik immün-inflamasyon indeksi gruplar arasında benzerdi $(\mathrm{P}=0.897)$. Ayrıca, pterjium grubunda korelasyon analizinde de hemogram parametreleri, nötrofil/lenfosit oranı, platelet/lenfosit oranı, sistemik immün-inflamasyon indeksi ve pterjium derecesi arasında istatistiksel olarak anlamlı ilişki olmadığı görüldü.

Sonuç: Çalışmamızın sonuçlarına göre pterjiumun sistemik inflamatuar etiyolojisini destekleyebilecek kanıt bulunamamıştır. Bu iki antite arasında ilişki olup olmadığını kesin olarak ortaya koyabilmek için geniş hasta popülasyonlarında yapılacak ileri randomize çalışmalara ihtiyaç vardır.

Anahtar Kelimeler: İnflamasyon; kan hücresi sayımı; konjonktiva; lenfositler; nötrofiller; piterjium.

\section{To Evaluate the Role of Systemic Inflammation on Conjunctival Pteryigum Etiopathogenesis}

\begin{abstract}
Aim: To assess the complete blood count parameters and blood-based systemic inflammatory markers in patients with conjunctival pterygium.

Materials and Methods: Thirty patients with conjunctival pterygium and 31 age and sex-matched control subjects included in the study. All patients underwent detailed ophthalmologic examination. Pterygium was also graded in pterygium group. Serum samples were obtained from all subjects, and neutrophillymphocyte ratio, plateletllymphocyte ratio and systemic immune-inflammation index were calculated. It is examined whether or not there exits an association between groups in terms of neutrophil count/percentage, lymphocyte count count, white blood cell count, mean platelet volume, red cell distribution width, platelet count, neutrophillymphocyte ratio, plateletlymphocyte ratio and systemic immune-inflammation index. The statistical assessment was performed with the assistance of Pearson's Chi-square test, Independent samples t-test, Mann-Whitney U test, Pearson and Spearman correlation analysis. $\mathrm{P}<0.05$ was considered statistically significant.
\end{abstract}

Results: The groups were similar in terms of cell counts. Although neutrophillymphocyte ratio and plateletlymphocyte 
ratio are slightly higher in pterygium group, this difference is not statistically significant (respectively $\mathrm{P}=0.141, \quad \mathrm{P}=0.480)$. Systemic immune-inflammation index was similar between groups $(\mathrm{P}=0.897)$. Moreover, no statistically significant correlation found among complete blood count parameters, neutrophilllymphocyte ratio, plateletlymphocyte ratio, systemic immuneinflammation index and grade of pterygium in the pterygium group.

Conclusion: According to our study results, no evidence supporting potential systemic inflammatory origin of pterygium was found. Further randomized studies with larger sample size are needed to discover if there is a relationship between these two entities.

Keywords: Blood cell count; conjunctiva; inflammation; lymphocytes; neutrophils; pterygium.

\section{GIRIS}

Pterjium konjonktiva dokusunun kornea üzerine üçgen şeklinde kontrolsüz bir biçimde büyümesi ile karakterize yaygın bir göz hastalığıdır $(1,2)$. Astigmatizmayı indüklemesi ve ileri vakalarda görsel aksı kapatması nedeniyle görmeyi ciddi bir şekilde etkileyebilir. Pterjium etiyolojisi tam olarak bilinmemekle birlikte patogenezde birçok faktör suçlanmaktadır. Bunlardan bazıları DNA onarımı ile ilgili genler (tümör süpresör gen p53 vb.), hücre proliferasyonu, migrasyonu ve anjiyogenezdir. Ek olarak Human papillomavirus (HPV) enfeksiyonu da suçlanan faktörler arasındadır $(3,4)$. Ancak yapılan birçok kapsamlı çalışmaya rağmen konjonktival pterjium etiyolojisi halen tam olarak aydınlatılamamıştır (5). İnflamasyonun pterjium etiyolojisindeki rolü ise tam olarak bilinmemekte ve popüler bir konu olarak araştırılmaktadır.

$\mathrm{Bu}$ çalışmada birçok hastalık için prognostik gösterge olarak kabul edilen kan temelli sistemik inflamasyon belirteçlerinin (kan hücre sayıları, hemoglobin, nötrofil/lenfosit oranı, eritrosit dağılım genişliği vb.) $(6,7)$ düzeylerinin saptanması ve bu belirteçler ile pterjium derecesi arasında ilişki olup olmadığını araştırmak amaçlanmıştır.

\section{GEREÇ VE YÖNTEMLER}

Çalışmaya Düzce Üniversitesi Tıp Fakültesi Göz Hastalıkları polikliniğinde konjonktival pterjium tanısı alan 30 hasta (pterjium grubu, PG) ve 31 sağl1klı gönüllü (kontrol grubu, KG) dahil edildi. Çalışma grubundaki olguların 18-65 yaş arasında olmasına ve konjonktival pterjium dışında herhangi bir sistemik/otoimmun hastalığı veya göz hastalığı olmamasına, kontrol grubundakilerin ise çalışma grubundaki olgular ile yaşcinsiyet uyumlu olmasına ve refraksiyon kusuru dışında herhangi bir göz hastalığına sahip olmamalarına ve ayrıca sistemik açıdan da tamamen sağlıklı olmalarına dikkat edildi. Kontrol grubundaki olgular göz polikliniğine refraksiyon muayenesi (uzak ya da yakın gözlüğü almak için) için başvuran hastalar arasından seçildi.

Tüm olgulara görme keskinliği-refraksiyon muayenesi, göz içi basınç ölçümü, biyomikroskopik inceleme, fundus muayenesini içeren standart göz muayenesi yapılıp sistemik hastalık varlığı sorgulandı. Ayrıca konjonktival pterjiumu olan olgularda pterjium derecelendirilmesi yapıldı. Olgulara çalışma ile ilgili detaylı bilgi verildi ve çalışmaya katılma yönünde gönüllü olanlardan gerekli onamlar alındıktan sonra hastane laboratuvar kayıtları incelendi. Son 1 aya ait hemogram sonucu olan hastaların verileri çalışmaya dahil edildi. Hemogram incelemelerinin rutin tarama amaciyla (ameliyat öncesi hazırlık, genel check-up muayenesi vb.) alınmış olmasına ve hastaların numunenin verildiği tarih itibariyle hemogram sonuçlarını etkileyecek patolojisi olmamasına dikkat edildi.

18 yaş altında ve 65 yaş üzerinde olanlar, gebeler (kadın olgular için), akut/kronik sistemik hastalığı olanlar, bilinen ya da tespit edilen akut/kronik göz hastalığ olanlar, göz ameliyatı geçirmiş olanlar, uzun süreli topikal/sistemik ilaç kullanım öyküsü olanlar ve sigara/alkol kullanıcıları çalışmadan dışlandı.

Olguların hemogram sonuçlarına bakılarak nötrofil/lenfosit oranı (NLO), platelet/lenfosit oranı (PLO) ve sistemik immün-inflamasyon indeksi (SII) hesapland1. Hesaplarda $\mathrm{NLO}=$ nötrofil sayısı /lenfosit say1s1, $\quad \mathrm{PLO}=$ trombosit say1s1/lenfosit say1s1 ve $\mathrm{SII}=$ nötrofil sayıs1 $\mathrm{X}$ trombosit sayıs1/lenfosit say1s1 formülleri kullanıldı (8). Pterjium derecelendirmesinde anormal konjonktival dokunun kornea üzerine ilerleme miktarına bakıldı. Pterjium dokusu kornea üzerine 2 milimetre (mm)' den daha az ilerlemiş ise Grade 1, 2-4 $\mathrm{mm}$ arasında ilerlemiş ise Grade 2 ve $4 \mathrm{~mm}$ 'den daha fazla ilerlemiş ise Grade 3 olarak değerlendirildi (9). Gruplar arasında nötrofil sayı-yüzdesi, lenfosit say1yüzdesi, hemoglobin $(\mathrm{Hb})$, eritrosit sayısı (RBC), lökosit sayıs1 (WBC), ortalama trombosit hacmi (MPV), eritrosit dağılım genişliği (RDW), trombosit sayısı (PLT), NLO, PLO, SII arasında ilişki olup olmadığg incelendi.

\section{Çalışmanın Etik Yönü}

Çalışmanın yapılabilmesi için Düzce Üniversitesi Girişimsel Olmayan Çalışmalar Etik Kurulundan etik kurul izni (Karar No: 2018/183), Düzce Üniversitesi Sağlık Uygulama Araştırma Merkezi Müdürlüğü’nden ve Düzce Üniversitesi Göz Hastalıkları Anabilim Dalı Başkanlığı'ndan gerekli yasal izinler alındı. Çalışmaya dahil edilen tüm olgulara çalışmanın amacı anlatıldıktan sonra Helsinki Bildirgesi'ne bağlı kalınarak yazılı izinleri temin edildi.

\section{İstatistiksel Analiz}

Verilerin istatistiksel değerlendirmesinde SPSS 21.0 (SPSS Inc, Chicago, IL, USA) analiz programı kullanıldı. Shapiro-Wilk testi ile değişkenlerin normal dağılıma uyup uymadığı değerlendirildi. Normal dağılıma uyan değerler ortalama \pm standart sapma (SS), normal dağılıma uymayan değerler ise ortanca (Q1: 1.kartil- Q3: 3.kartil) şeklinde sunuldu. Niteliksel verilerin karşılaştırılmasında Ki-kare testi; niceliksel (ölçümsel) verilerin karşılaştırılmasında ise normal dağılıma uyan verilerde Bağımsız Örneklemler t testi, normal dağılıma uymayan verilerde ise Mann-Whitney $U$ testi kullanıldı. Değişkenler arasındaki ilişkiler Pearson ve Spearman korelasyon analizleri ile incelendi. Tüm istatistiksel analiz yöntemlerinde sonuçlar \%95'lik güven aralığında değerlendirildi. $\mathrm{p}<0.05$ istatistiksel olarak anlamlı kabul edildi.

\section{BULGULAR}

Ortalama yaş $\mathrm{PG}^{\prime} \mathrm{da} \quad 44.87 \pm 11.39$ yıl, KG'da ise $45.48 \pm 8.68$ yıl olup gruplar demografik açıdan benzerdi 
(Tablo 1). Nötrofil say1-yüzdesi, lenfosit say1-yüzdesi, $\mathrm{Hb}, \mathrm{RBC}$, WBC, MPV, RDW ve PLT ortalamaları arasında anlamlı fark yoktu (Tablo 2,3).

NLO ve PLO pterjium grubunda hafifçe yüksek olmakla birlikte bu fark istatistiksel açıdan anlamlı değildi. SII bakımından gruplar benzerdi (Tablo 3).

Tablo 1. Demografik veriler ve pterjium derecesi

\begin{tabular}{|c|c|c|c|c|}
\hline \multicolumn{2}{|c|}{ Parametreler } & $\begin{array}{c}\text { Pterjium } \\
\text { Grubu } \\
(n=30)\end{array}$ & $\begin{array}{c}\text { Kontrol } \\
\text { Grubu } \\
(n=31)\end{array}$ & $\underset{\text { Değeri }}{\mathbf{P}}$ \\
\hline \multicolumn{2}{|l|}{ Yaș $^{\mathrm{a}}$} & $44.87 \pm 11.39$ & $45.48 \pm 8.68$ & $0.812^{b}$ \\
\hline \multirow{2}{*}{$\begin{array}{l}\text { Cinsiyet } \\
\text { (sayı, \%) }\end{array}$} & Kadın & $17(\% 57)$ & $22(\% 71)$ & \multirow{2}{*}{$0.245^{c}$} \\
\hline & Erkek & $13(\% 43)$ & $9(\% 29)$ & \\
\hline \multicolumn{2}{|c|}{ Pterjium Evresi $^{\mathrm{d}}$} & $1(1-2)$ & - & - \\
\hline
\end{tabular}

Tablo 2. Tam kan hücre sayıları

\begin{tabular}{|c|c|c|c|}
\hline Parametreler $^{\mathbf{a}}$ & $\begin{array}{c}\text { Pterjium } \\
\text { Grubu } \\
(n=30)\end{array}$ & $\begin{array}{c}\text { Kontrol } \\
\text { Grubu } \\
(n=31)\end{array}$ & $\underset{\text { Değeri }^{\mathrm{t}}}{\mathbf{P}}$ \\
\hline Nötrofil Sayısı & $4.26 \pm 0.97$ & $4.29 \pm 0.95$ & 0.890 \\
\hline $\begin{array}{l}\text { Nötrofil } \\
\text { Yüzdesi }\end{array}$ & $59.63 \pm 4.97$ & $58.27 \pm 6.55$ & 0.366 \\
\hline Lenfosit Sayısı & $2.25 \pm 0.47$ & $2.4 \pm 0.59$ & 0.251 \\
\hline $\begin{array}{l}\text { Lenfosit } \\
\text { Yüzdesi }\end{array}$ & $31.8 \pm 5.02$ & $32.9 \pm 6.24$ & 0.466 \\
\hline RBC & $4.88 \pm 0.46$ & $4.73 \pm 0.38$ & 0.171 \\
\hline WBC & $7.11 \pm 1.31$ & $7.24 \pm 1.23$ & 0.693 \\
\hline PLT & $281.33 \pm 74.03$ & $282.16 \pm 57.33$ & 0.961 \\
\hline
\end{tabular}

Tablo 3. Tam kan sayımı verileri ve bazı oranlar

\begin{tabular}{|c|c|c|c|}
\hline Parametreler $^{\mathrm{a}}$ & $\begin{array}{c}\text { Pterjium } \\
\text { Grubu } \\
(\mathbf{n}=30)\end{array}$ & $\begin{array}{c}\text { Kontrol } \\
\text { Grubu } \\
(n=31)\end{array}$ & $\underset{\text { Değeri }^{\mathrm{b}}}{P}$ \\
\hline $\mathbf{H b}$ & $\begin{array}{c}13.9 \\
(12.7-15.5)\end{array}$ & $\begin{array}{c}13.8 \\
(13.3-15.1)\end{array}$ & 0.960 \\
\hline RDW & $\begin{array}{c}13.4 \\
(13.1-13.9)\end{array}$ & $\begin{array}{c}13.5 \\
(12.5-13.9)\end{array}$ & 0.444 \\
\hline MPV & $\begin{array}{c}9.8 \\
(8.9-10.6)\end{array}$ & $\begin{array}{c}9.7 \\
(9-10.6)\end{array}$ & 0.902 \\
\hline NLO & $\begin{array}{c}1.9 \\
(1.6-2.1)\end{array}$ & $\begin{array}{c}1.8 \\
(1.4-2.1)\end{array}$ & 0.141 \\
\hline PLO & $\begin{array}{c}121.7 \\
(110.5-142.9)\end{array}$ & $\begin{array}{c}116.3 \\
(104.9-136.7)\end{array}$ & 0.480 \\
\hline SII & $\begin{array}{c}482.9 \\
(428.1-636.9)\end{array}$ & $\begin{array}{c}526.5 \\
(402.8-627.1)\end{array}$ & 0.897 \\
\hline \multicolumn{4}{|c|}{$\begin{array}{l}\text { a: ortanca (Q1: 1.kartil- Q3: 3.kartil), }{ }^{\text {b}}: \text { Mann-Whitney U testi, } \\
\text { Hb: hemoglobin, RDW: eritrosit dağılım genişliği, MPV: ortalama } \\
\text { trombosit hacmi, NLO: nötrofil/lenfosit oranı, PLO: platelet/lenfosit } \\
\text { oranı, SII: sistemik immün-inflamasyon indeksi }\end{array}$} \\
\hline
\end{tabular}

Ayrica, pterjium grubunda korelasyon analizinde de hemogram parametreleri, NLO, PLO, SII ve pterijium derecesi arasında istatistiksel olarak anlamlı ilişki olmadığı görüldü (Tablo 4).
Tablo 4. Pterjium grubunun demografik-klinik verileri ile tam kan sayımı değerleri ve bazı oranlar arasındaki ilişki

\begin{tabular}{|l|c|c|c|c|}
\hline & \multicolumn{2}{|c|}{ Yaş } & Pterjium Evresi \\
\hline & $\mathbf{r}$ & $\mathbf{P}$ & $\mathbf{r}$ & $\mathbf{P}^{\mathbf{b}}$ \\
\hline Nötrofil Sayısı & -0.135 & $0.477^{\mathrm{a}}$ & -0.079 & 0.544 \\
\hline Nötrofil Yüzdesi & 0.02 & $0.918^{\mathrm{a}}$ & 0.134 & 0.304 \\
\hline Lenfosit Sayısı & -0.138 & $0.467^{\mathrm{a}}$ & -0.141 & 0.277 \\
\hline Lenfosit Yüzdesi & -0.025 & $0.895^{\mathrm{a}}$ & -0.111 & 0.394 \\
\hline RBC & -0.094 & $0.642^{\mathrm{a}}$ & 0.156 & 0.243 \\
\hline WBC & -0.161 & $0.396^{\mathrm{a}}$ & -0.091 & 0.488 \\
\hline PLT & -0.111 & $0.558^{\mathrm{a}}$ & -0.099 & 0.448 \\
\hline Hb & 0.300 & $0.107^{\mathrm{b}}$ & -0.039 & 0.766 \\
\hline RDW & -0.011 & $0.953^{\mathrm{b}}$ & 0.132 & 0.309 \\
\hline MPV & -0.236 & $0.209^{\mathrm{b}}$ & -0.007 & 0.955 \\
\hline NLO & 0.005 & $0.980^{\mathrm{b}}$ & 0.151 & 0.246 \\
\hline PLO & -0.007 & $0.969^{\mathrm{b}}$ & 0.061 & 0.643 \\
\hline SII & -0.359 & $0.051^{\mathrm{b}}$ & -0.042 & 0.750 \\
\hline $\begin{array}{l}\text { a }: \text { Pearson korelasyon analizi, } \\
\text { korelasyon katsayis1, P: P değeri }\end{array}$ \\
\hline
\end{tabular}

\section{TARTIŞMA}

Pterjium halk arasında 'göze et yürümesi' ya da 'gözde et büyümesi' ismi ile bilinen oldukça sık olarak görülen bir oküler yüzey hastalığıdır. Özellikle açık havada çalışan ve ultraviyole (UV) 1şı̆̆ına çok maruz kalan kişilerde daha yaygın olarak karşımıza çıkmaktadır. Erken aşamalarında sadece estetik bir problem teşkil etmekle birlikte ilerleyen dönemlerde kronik oküler irritasyon, görme aksını kapatma, astigmatizmayı tetikleme gibi nedenlerle görme düzeyini ve dolayısıyla yaşam kalitesini ciddi derecede etkiler hale gelebilir (1).

Ülkemizde yaklaşık \%2-4 oranında görülen pterjiumun klasik tedavisi cerrahidir. Pterjium tedavisi ile ilgili en büyük problem ise \%80'lere varabilen yüksek rekürrens oranlarıdır. Bu özelliği nedeniyle aslında iyi huylu bir lezyon olmakla birlikte malignitelere benzer şekilde rekürrenslerle giden agresif seyir gösterebilmektedir (2). Hastalığın etyopatogenezinde bilinen en güçlü etken yoğun UV maruziyetidir. Bunun yanında kalıtım, oksidatif stres, DNA hasar1, proliferasyon, neovaskülarizasyon gibi başka patolojik süreçlerin de etkili olduğu söylenmekte ve hastalık multifaktoriyel kökenli olarak tanımlanmaktadır (10). Hatta bazı çalışmalarda histopatolojik doku örneklerinde lokal inflamasyonun pterjium gelişimi ile sıkı ilişkisi gözler önüne serilmiştir.

Sistemik inflamasyonun patogenezdeki rolü ise son zamanlarda merak konusu olmuştur (11). Bu konu ile ilgili literatürde az sayıda hücresel temelli çalışma mevcuttur. Lee ve ark. (12) yaptıkları ön segment floresein anjiyografi destekli çalışmalarında vaskülogeneziste önemli olan endoteliyal progenitör hücrelerin pterjiumlu olguların hem serum örneklerinde hem de pterjium dokusunun kendisinde artmış olduğunu bulmuşlardır. Benzer şekilde Kim ve ark. (13) yaptıkları başka bir çalışmada pterjiumu potansiyel sistemik kökenli bir oküler hastalık olarak tanımlamış ve pterjium dokusundaki fibroblastların kökeni olabileceğini düşündükleri kemik iliği kökenli progenitör hücrelerin düzeyini araştırmışlardır. Ve çalışmanın sonunda pterjiumun immun-inflamatuar kökeni olabileceği yorumunda bulunmuşlardır. $\mathrm{Bu}$ noktada iki önemli tartışma konusu pterjiuma neden olan hücrelerin nereden 
geldiği ve pterjium oluşumunu başlatan esas tetikleyici faktör ya da faktörlerin ne olduğudur.

İnflamasyon esas olarak vücudun immun cevabının bir parçası ve hatta iyileşme sürecinin başlangıcı olmakla birlikte kronikleştiğinde kanserler ve romatolojik hastalıklar başta olmak üzere birçok hastalığa da davetiye çıkaran ve önemsenmesi gereken bir doku reaksiyonudur (14). Sistemik inflamasyon taramasında kan temelli sistemik inflamasyon belirteçlerinin önemi büyüktür. $\mathrm{Hb}$, lökositler, trombositler, nötrofiller ve lenfositler bunlardan bazılarıdır (6,15). MPV de temel olarak trombosit fonksiyon ve aktivitesini göstermekle birlikte immünolojik/inflamatuar birçok olayda önemli rol oynadığı tespit edilmiştir (16). NLO, PLO ve SII indekslerinin ise kanser başta olmak üzere özellikle inflamatuar ve kardiyovasküler hastalıklar gibi birçok durumda kullanılabilirliği keşfedilmiştir (17-19). Hatta keratokonus, glokom, yaşa bağlı maküla dejenerasyonu ve retinal vasküler tıkanıklıklar gibi oküler hastalıklarla da ilişkisini gösteren çalışmalar mevcuttur (20-23). Bunlar arasında SII, yakın zamanda tanımlanmış olması ve özellikle kanser olgularında kullanışlı bir prognostik belirteç olduğunun gösterilmiş olması bakımından ayrı bir öneme sahiptir.

Pterjiumlu olgularda NLO ile ilgili literatürde bir adet taze yayin mevcuttur. Atilgan Ucgul ve ark. (24) tarafından yapılan bu çalışmada pterjium ameliyatı yapılan 200 olgunun hemogram sonuçları retrospektif olarak incelenmiş ve şaşılık nedeniyle opere edilen hastaların değerleri ile karşılaştırılmıştır. Yapılan analizde iki grup arasında oranlar benzer bulunmuş ve NLO'nun pterjium hastalığının bağımsız bir belirteci olmadığı sonucuna ulaşılmıştır. Fakat çalışmada sadece NLO değerlendirilmiş, pterjium derecesi ile NLO arasındaki ilişkiye bakılmamıştır. Hatta son söz olarak bu konunun gelecek çalışmalarda mutlaka araştırılması gerektiği vurgulanmıştır.

Çalışmamızın en önemli üstün yanı hücre sayıları ve NLO'ya ek olarak PLO ve SII gibi daha güncel oranların da değerlendirilmiş olması ve bu değerlerin pterjium derecesi ile ilişkisinin detaylı olarak karşılaştırılmasıdır. Ayrıca bizim çalışmamızda kontrol grubu olarak hem oküler hem de sistemik yönden tamamen sağlıklı olgular değerlendirilmiştir. Çalışmamızın en önemli eksik yönü ise nispeten az olgu sayısıdır. Her ne kadar istatistiksel anlamlılık düzeyine erişilemese de NLO ve PLO oranlarının pterjium grubunda az da olsa yüksek olduğu görülmüştür. Bu sonuç pterjiumun sistemik inflamatuar temeline olan merakın boşuna olmadığını, daha geniş çaplı çalışmalar ile tekrar araştırılması gerektiğini telkin etmektedir.

\section{SONUÇ}

$\mathrm{Bu}$ çalışma sonucunda pterjiumun sistemik inflamatuvar etiyolojisini destekleyebilecek kanıt bulunamamıştır. Daha geniş hasta popülasyonunda yapılacak ileri randomize çalışmalar ile bu sorunun cevabı kesin olarak ortaya konabilir.

\section{KAYNAKLAR}

1. Liu T, Liu Y, Xie L, He X, Bai J. Progress in the pathogenesis of pterygium. Curr Eye Res. 2013; 38(12): 1191-7.

2. Malozhen SA, Trufanov SV, Krakhmaleva DA. Pterygium: Etiology, pathogenesis, treatment. Vestn Oftalmol. 2017; 133(5): 76-83.

3. Di Girolamo N. Association of human papilloma virus with pterygia and ocular-surface squamous neoplasia. Eye (Lond). 2012; 26(2): 202-11.

4. Coroneo MT. Pterygium as an early indicator of ultraviolet insolation: A hypothesis. Br J Ophthalmol. 1993; 77(11): 734-9.

5. Bradley JC, Yang W, Bradley RH, Reid TW, Schwab IR. The science of pterygia. Br J Ophthalmol. 2010; 94(7): 815-20.

6. Fankhauser CD, Sander S, Roth L, Gross O, Eberli D, Sulser T, et al. Systemic inflammatory markers have independent prognostic value in patients with metastatic testicular germ cell tumours undergoing first-line chemotherapy. Br J Cancer. 2018 20; 118(6): 825-30.

7. Yao C, Zhang Z, Yao Y, Xu X, Jiang Q, Shi D. Predictive value of neutrophil to lymphocyte ratio and platelet to lymphocyte ratio for acute deep vein thrombosis after total joint arthroplasty: A retrospective study. J Orthop Surg Res. 2018; 13(1): 40.

8. Feng JF, Chen S, Yang X. Systemic immuneinflammation index (SII) is a useful prognostic indicator for patients with squamous cell carcinoma of the esophagus. Medicine (Baltimore). 2017; 96(4): e5886.

9. Kanski JJ. Clinical ophthalmology. A systematic approach. 6th ed. Philadelphia, PA, Pennsylvania: Butterworth- Heinemann; 2007.

10. Anguria P, Kitinya J, Ntuli S, Carmichael T. The role of heredity in pterygium development. Int $\mathrm{J}$ Ophthalmol. 2014; 7(3): 563-73.

11. Golu T, Mogoantă L, Streba CT, Pirici DN, Mălăescu D, Mateescu GO, et al. Pterygium: Histological and immunohistochemical aspects. Rom J Morphol Embryol. 2011; 52(1): 153-8.

12. Lee JK, Song YS, Ha HS, Park JH, Kim MK, Park AJ, et al. Endothelial progenitor cells in pterygium pathogenesis. Eye (Lond). 2007; 21(9): 1186-93.

13. Kim KW, Park SH, Kim JC. Fibroblast biology in pterygia. Exp Eye Res. 2016; 142: 32-9.

14. Fougère $B$, Boulanger $E$, Nourhashémi F, Guyonnet S, Cesari M. Chronic Inflammation: Accelerator of Biological Aging. J Gerontol A Biol Sci Med Sci. 2017; 72(9): 1218-25.

15. Reuben DB, Cheh AI, Harris TB, Ferrucci L, Rowe JW, Tracy RP, et al. Peripheral blood markers of inflammation predict mortality and functional decline in high-functioning community-dwelling older persons. J Am Geriatr Soc. 2002; 50(4): 638-44.

16. Briggs C. Quality counts: Ew parameters in blood cell counting. Int J Lab Hematol. 2009; 31(3): 277-97.

17. Pichler M, Hutterer GC, Stoeckigt C, Chromecki TF, Stojakovic T, Golbeck S, et al. Validation of the pretreatment neutrophil-lymphocyte ratio as a prognostic 
factor in a large European cohort of renal cell carcinoma patients. Br J Cancer. 2013; 108(4): 901-7.

18. Tamhane UU, Aneja S, Montgomery D, Rogers EK, Eagle KA, Gurm HS. Association between admission neutrophil to lymphocyte ratio and outcomes in patients with acute coronary syndrome. Am J Cardiol. 2008; 102(6): 653-7.

19. Templeton AJ, Ace O, McNamara MG, Al-Mubarak M, Vera-Badillo FE, Hermanns T, et al. Prognostic role of platelet to lymphocyte ratio in solid tumors: A systematic review and meta-analysis. Cancer Epidemiol Biomarkers Prev. 2014; 23(7): 1204-12.

20. Karaca EE, Özmen MC, Ekici F, Yüksel E, Türkoğlu Z. Neutrophil-to-lymphocyte ratio may predict progression in patients with keratoconus. Cornea. 2014; 33(11): 1168-73.

21. Ozgonul C, Sertoglu E, Mumcuoglu T, Kucukevcilioglu M. Neutrophil-to-Lymphocyte ratio and Platelet-to-Lymphocyte ratio as novel biomarkers of primary open-angle glaucoma. J Glaucoma. 2016; 25(10): e815-e820.

22. Ilhan N, Daglioglu MC, Ilhan O, Coskun M,Tuzcu EA, Kahraman $\mathrm{H}$ et al. Assessment of Neutrophil/Lymphocyte Ratio in Patients with Agerelated Macular Degeneration. Ocul Immunol Inflamm. 2014; 23(4): 1-4.

23. Dursun A, Ozturk S, Yucel H, Ozec AV, Dursun FG, Toker MI, et al. Association of neutrophil/lymphocyte ratio and retinal vein occlusion. Eur J Ophthalmol. 2015; 25(4): 343-6.

24. Atilgan Ucgul C, Kosekahya P, Tekin K, Sendul SY, Caglayan M, Goker YS, et al. The Evaluation of Neutrophil-to-Lymphocyte Ratio as a Novel Marker in Patients with Pterygium. Turkiye Klinikleri J Ophthalmol. 2019. Article in press. Available from: https://www.turkiyeklinikleri.com/inpress_article/enthe-evaluation-of-neutrophil-to-lymphocyte-ratio-asa-novel-marker-in-patients-with-pterygium85477.html. 